\title{
Genders at Work: Gender as a Geography of Power in the Academy
}

\author{
Kate Carruthers Thomas
}

STARTING POINTS

I have an unusual dual role within a large, urban, modern UK university. As a Senior Research Fellow, I work critically on gender, drawing on geographical, sociological and educational theories and methods. As the university's Project Manager for the Athena SWAN Charter, I work in gender, overseeing and innovating activities in relation to the HE sector's flagship accreditation system for advancing gender equality. As such, I am 'doing diversity work ... the ordinary and painstaking work of working on institutions so they are more accommodating' (Ahmed 2017). Some colleagues express surprise at this juxtaposition and wonder how the two are compatible? Indeed, as Ahmed writes: 'working in-house too often ends up being a restoration project, polishing the furniture so it appears less damaged; a labour I have called ... "institutional polishing"' (Ahmed 2018).

My current research: Gender(s) at Work, investigates how gender operates as a geography of power in the contemporary academy, particularly in relation to notions of 'career'. This chapter first contextualises the research within the intertwining contexts of higher education (HE) and the Athena SWAN Charter. It then outlines how theories of 'the spatial', notably Massey's understanding of space as 'a simultaneity of stories-sofar and places as collections of those stories' (2005, p. 11) shape my key research questions and methodology. A series of selected 'stories-so-far' illustrates the complexity and dimensionality of lived, gendered experiences in the academy. Throughout and in conclusion, I reflect upon the alignments and tensions in my work and the opportunities these afford to resist sexism in the academy.

\section{CONTEXT}

\section{The Project}

Gender(s) at Work constitutes institutional research in that it is conducted within an educational organisation to inform decision-making, planning and effectiveness. Certainly, the project aims to increase corporate intelligence about gender equality and contribute to the university's Athena SWAN gender equality agenda. However, institutional research typically seeks a quick turnaround and clear simple answers and is not underpinned by theoretical perspectives (Brown and Jones 2015). Gender(s) at Work is distinctive in its duration (18 months); in being theoretically underpinned by theories and principles of feminist geography and, as evidenced by this chapter, reporting its findings beyond the university's walls. It is qualitative in character, collecting data via face-to-face individual interviews and a visual mapping task.

45 participants were recruited following an open call for staff participants of all genders, in academic and professional services roles at all levels of seniority across the university hierarchy. Of these, 31 (68\%) participants were in academic/academic management roles; 14 (32\%) in professional services/professional services management roles. 27 (60\%) of the participants identified as female, $16(35 \%)$ as male, 1 as gender non-binary and 1 as transgender. 36 (80\%) of the participants identified as White, 9 (19\%) as Black and Minority Ethnic (BAME). 28\% of participants were aged $30-39$ years, $28 \% 40-49$ years, $26 \% 50-59$ years, $13 \% 18-29$ years, and one 60-69 years.

\section{Higher Education}

Contemporary HE originates from 'a world without women' (Noble 1992); the enclosed masculine societies of the monasteries and early universities, engaged in 'the kind of knowledge production which was to receive the highest social valuation' (Massey 1998 p. 161). Our universities continue to be specialised places of knowledge production, but they are now, most definitely, worlds with women; albeit under-represented in particular disciplinary spaces and the higher echelons of management (ECU 2017; Jarboe 2016; Blackmore et al. 2015 inter alia). Massification, marketization, metrics and technological advances continually intensify pressure on 
academics to 'reproduce and enhance the value of their own labour power by keeping up with the literature, going to conferences, maintaining the performance of networking' (Massey 1998). However, staff in HE (as elsewhere) also continue to negotiate paid workload and 'career' within the constraints of social roles coded 'masculine' and 'feminine'. Daily experiences of working in HE play out in complex border territory between polarised structures of work and home.

Nevertheless, the prevailing academic culture relies on a model of carelessness: 'the idealized worker is one that is available 24/7 without ties or responsibilities that will hinder her or his productive capacities. She or he is unencumbered and on-call, even if not "at work"' (Lynch 2010, p. 57). Assumptions of carelessness also inform the generic, gender-neutral model of 'career' in terms of an occupation undertaken for a significant period of an individual's life, with opportunities for progress. This implies a set and bounded vertical trajectory with a finishing line, or at least a desired end point. The notion of 'career' is frequently associated with linear metaphors (pipeline, ladder, trajectory); which aligned to 'male-defined constructions of work and career success ... continue to dominate organisational research and practice' (Bilimoria et al. 2010, p. 727). However, Allen and Castleman (2001) argue the idea of career pipeline is a fallacy, because even with a critical mass of 'appropriate' women, the pipeline is leaky with significant dead-ends.

Gender inequality in the academy is well-documented within a vigorous, transnational body of literature (Acker 2006; Bagilhole 2002, 2007; Blackmore 2014; Morley 2013, 2014, 2016; Morley and David 2009; O'Connor 2014; White and O'Connor 2017 inter alia); and weighted towards disadvantages faced by female academics working within 'exclusionary structures and practices and seemingly entrenched gender power relations' (Burkinshaw and White 2017). An emerging strand of UK literature addresses intersections of gender and ethnicity as experienced by Black and Minority Ethnic (BAME) female academics (Bhopal 2016; Tate and Bagguley 2017; Gabriel and Tate 2017). Female undergraduate participation in the global academy is at record levels (Morley 2013) yet women remain woefully under-represented in senior academic and leadership positions in the sector (Morley 2013, Jarboe 2016 inter alia). In the UK, the sector's average gender pay reflects the national average of $18.4 \%$ (Jones 2018).

In no small part due to the gendered order of caring (Lynch and Feely 2009) female academics tend to have atypical career patterns and diverse routes into the academy. They are also more likely to pick up teaching and pastoral duties and institutional housekeeping, e.g. committee work and administration (Coate et al. 2015), which disadvantage them in terms of time available for research. In the UK, evidence of differential selection, submission and status in relation to the Research Excellence Framework (REF) demonstrate that factors of disability, age, nationality and career stage intersect with gender to exacerbate disadvantage (Yarrow 2017, HEFCE 2015). Yet, research is the most valuable currency in HE's prestige economy (Coate et al. 2015; Morley 2014) and performance-centred culture.

\section{The Athena SWAN Charter}

The Athena SWAN Charter is a sector initiative first established in the UK in 2005 and co-ordinated by the centrally funded Equality Challenge Unit (ECU), as a mechanism to address gender inequality in the HE workplace. The Charter's six principles aim to 'encourage and recognise commitment to advancing the careers of women in science, technology, engineering, maths and medicine (STEMM) and their employment in higher education and research' (Advance HE 2018a). It specifically targets the phenomenon of the 'leaky' career pipeline, whereby across academia, even in subjects popular with women at undergraduate and postgraduate level, the percentage of females decline significantly along the career ladder from PhD student to Professor and from junior to senior management.

Athena SWAN provides a vehicle for individual universities and research centres to assess their policies and practices, plan actions to mitigate structural inequalities and advance career progression. Institutions progress through a system of Bronze, Silver and Gold institutional and departmental awards. The Charter preceded new UK equalities legislation in 2010 and has since become part of universities' wider strategies of and business case for, equality, diversity and inclusion. During this period, more complex equalities discourses challenging the gender binary and highlighting intersectionality, have gained traction and in May 2015 Athena SWAN's UK framework 'was expanded to recognise gender equality more broadly ... and work undertaken in arts, humanities, social sciences, business and law (AHSSBL), and in professional and support roles, and for trans staff and students' (Advance HE 2018a). The Gender(s) at Work participant sample reflects this expanded framework. Four new Charter principles were added, including a commitment to consider intersectionality. These changes have not been universally welcomed, with some claiming a broader gender equality remit blurs focus and creates tensions between addressing female disadvantage and providing equal opportunities for all (Carruthers Thomas 2018). 
Athena SWAN Charter membership in the UK has grown from ten founding institutions in 2005 to 145 in 2018 (Advance HE 2018b). In 2015, the Charter was adopted by universities in the Republic of Ireland and a pilot launched in Australia by the Science in Australia Gender Equity (SAGE) Initiative in partnership with the Academy of Technology and Engineering (ATSE). The Australian pilot involved 40 universities and used the pre-May 2015 (STEMM only) framework. Meanwhile in 2018, Advance HE, a new agency formed from the merger of ECU, the Higher Education Academy (HEA) and the Leadership Foundation for Higher Education (LFHE), announced an independent review of the Charter to ensure 'it is fit for current and future needs of institutions, individuals and the sector as a whole' (Advance HE 2018c). The review prioritises sector concerns about workload, consistency in peer-review panels and the inclusion of non-STEMM disciplines in the framework. However, Athena SWAN's core focus: the leaky career pipeline and women's progression against conventional measures of academic 'success' is not under review.

\section{THEORY TO PRACTICE}

\section{Massey on Space}

The ideas of radical geographer Doreen Massey (1944-2016) are central to Gender(s) at Work. Massey is a key figure in the diverse project of feminist geography, whose broad aim is 'to investigate, make visible and challenge the relationships between gender divisions and spatial divisions, to uncover their mutual constitution to problematise their apparent naturalness' (McDowell 1999, p. 12). Massey defines space 'as social relations shaped by power and inherently temporal ... a confluence and product of histories, relationships ... the sphere in which distinct trajectories coexist' $(2005$, p. 9). Massey brings space and power together through the heuristic device of 'activity space' - the spatial network of links and activities, of spatial connections and of locations, within which a particular agent operates... within each activity space is a geography of power' (Massey 2005, p. 55). Activity space operates on multiple scales. It frames 'the academy' as the product of social relations shaped by (geographies of) power socially coded masculine, i.e. academic and disciplinary discourses, tradition, patriarchy and government. Individual universities are activity spaces in their own right, positioned more or less powerfully within those wider networks and crosscut by their own geographies of power.

\section{Spatial Storytelling}

The methodological design of Gender(s) at Work reflects Massey's concept of space as plural, heterogeneous and fluid. It is also informed by the work of essayist and psychogeographer Rebecca Solnit (2001, 2006, 2010, 2013) who experiments with spatial storytelling in her reinterpretation of the atlas as a visual, textual and literary form created by multiple authors and artists 'a collection of versions of a place, a compendium of perspectives' (2010, p. vii). Solnit re-presents cities in a way which "unsettles "the classic Western map" ... disputes the internal coherence, the singular uniformity to which the classical map lays claim' (Massey 2005, p. 109).

I first experimented with spatial storytelling as part of my doctoral research, using mapping in its broadest sense - as process, product and powerful metaphorical tool to capture mature part-time undergraduates' sense of belonging in HE on campus maps (Carruthers Thomas, in press; Thomas 2016). I subsequently developed the practice of organisational cartographies, as a way of 'mapping the university as a space of multiple centres experienced in multiple ways, thus capturing a wider, more complex organisational territory' (Carruthers Thomas 2017). Spatial storytelling allows exploration of spaces between rhetoric and experience; it loosens the hold of the binary. As a research methodology it is both instrumental and illustrative, engaging with the material and imaginary; the past, present and future.

In Gender(s) At Work spatial storytelling foregrounds relationships between space and power in considering lived experiences of work and career. Narrative enquiry and visual mapping tools are interwoven to elicit the multiple and the psychosocial: the mutual interaction of individuals of multiple gender identities with the gendered social environment of the university. Spatial storytelling challenges space and place as natural and coherent, disrupt prevailing narratives and uncover the peripheral, the hidden, the contradictory - the 'spaces between' of the university workplace, 'a highly specialised envelope of space-time, into which the intrusion of other activities and interests is unwanted and limited' (Massey 1998, p.109).

\section{In Practice: Narrative}

Narrative enquiry begins with experiences as expressed in lived and told stories of individuals and relates to the singular and particular within a social context (Creswell 2007). In Gender(s) At Work this approach foregrounds 
the way(s) participants create meaning of their lived experiences of work and 'career' in HE. Each interviewee was first asked to provide a 'potted history' of their work and career. The interview then followed a common schedule of questions and prompts exploring interviewees' experiences of working at the university and in the HE sector generally. They were asked to reflect on their perceptions of the impact, or otherwise, of gender on those experiences. Interviewees are 'both living their stories in an ongoing experiential text and telling their stories in words as they reflect upon life and explain themselves to others' (Connelly and Clandinin 1990, p. 3). Narrative enquiry allows for complexities, inconsistencies and silences. 'An essential aspect of data is that ... good narratives ... reveal ambiguity rather than tidy it away' (Bathmaker 2010, p. 2). Narrative is also central to the role of the researcher whose privilege it is to elicit, listen to and restory individuals' stories so that 'the thing finally written on paper ... the research paper or book, is a collaborative document; a mutually constructed story created out of the lives of both researcher and participant' (Connelly and Clandinin 1990, p. 12).

\section{In Practice: Mapping}

The visual mapping tool draws on participatory diagramming, a technique widely used in social geography and development studies which is 'wide open to context- and topic-specific innovations by researchers and participants alike' (Kesby 2000, p. 425). Mapping in its dominant form is problematic in that it gives authority to simplified, selective and bounded representations of space, and positions 'the observer, themselves unobserved, outside and above the object of the gaze' (Massey 2005, p. 107). However, in this mapping activity, the interviewee is both agentic and acknowledged as the map maker.

Each interviewee was given a pen and a mapping sheet containing three shapes: a triangle with a solid outline, a circle with a dotted outline and a rectangle shaded blue with a solid outline. They were asked to select the shape they felt best represented the university and to position themselves in relation to that shape. Interviewees were free to make any changes, add text, use more than one shape or create their own visual representation. The activity was therefore prescriptive in its use of familiar shapes, but flexible in the shapes' varied characteristics and in giving the interviewee the option to modify them or create alternatives.

Acts of distancing and disrupting reveal the 'spaces between' of the university workplace:

Participant-generated visual materials are particularly helpful in exploring the taken-for-granted things in their research participants' lives ... [it] involves the participants reflecting on their activities in a way that is not usually done; it gives them distance from what they are usually immersed in and allows them to articulate thoughts and feelings that usually remain implicit.

Rose 2014, p. 27.

Interviewees used the given shapes to represent their perceptions of the organisation, for example, hierarchical (the triangle), porous (the circle). Visually and through accompanying narratives they positioned themselves in relation to organisational power structures (geographies of power) and indicated affective, psychosocial dimensions of their experiences. The activity often triggered fresh thoughts and discussions as well as sometimes leading interviewees to revisit and extend topics or themes already covered. The exercise also highlighted synergies and conflicts between the professional and personal, internal and external.

\section{STORIES-SO-FAR}

The following section presents a small selection of stories-so-far, narrated by six participants, five female and one male. These explore ways of telling and reading the 'spatial' in stories of work and career, and how these contribute to understanding how gender operates as a geography of power in contemporary HE. The stories-sofar are interspersed with my own reflections on ways in which these provoke tensions and alignments within my professional role and the opportunities these afford to resist sexism in the academy. Pseudonyms are used, but job type, stated gender identity, ethnicity and age group are included.

\section{Narrating Career}

Interviewees' constructions of potted career histories at the start of each interview initiated a wider mapping of professional and personal identities.

There's a lot of bits and pieces to my career. When l look back, there are themes, but it was very broken. I kept starting jobs and leaving jobs and then I started my PhD. I'm a Research Assistant and officially I'm employed to support other staff on their projects but there is a day a week that I can sort of carve out my own research. It's obviously much messier than that in practice. It's a constant process of trying 
to make sense of what's going on and what is this environment that I'm in and how can I make sure that I position myself to boost my profile? My profile is terrible in terms of publications.

Yvonne, Research Assistant, Female, White British, 40+ years

Yvonne has a sense of where she 'should' be in the competitive, individualised environment of the academy but finds herself far behind the field. She embarked 'late' on an academic career and is notably short of its principal currency, publications. She chooses the circle and maps herself on the periphery.

I've chosen the circle instead of the triangle because it seems less claustrophobic. This looks like you can go home to your life outside. I'm here, a little spot. I don't feel geographically in the centre in terms of the campus I'm on ... and at the moment, I haven't established solid partnerships or relationships with people.

Yvonne

Anne, in the same age group as Yvonne, occupies a significantly more senior role, but has diverted from a conventional academic trajectory in order to get a permanent contract:

My career history? Research assistant, PhD, post doc, lecturer - then I was invited to apply for an academic-related role. As it was permanent, and having never at that point had a permanent job, thought, "What have I got to lose?" It gave me an opportunity to work cross-university and at a much more senior level. That's what gave me the experience to do the jobs I've done since. Then it's been quite a zigzag route to this point.

Anne, Senior Academic Manager, Female, White British, 40+ years

Anne also chooses the circle but unlike Yvonne, places herself at the centre of it.

I'm going to go for the circle, because the way I see academia is as a conglomerate: as a collegiate activity. I would place myself, I think, at the centre of that - not because I think I'm the centre of everything - but the way I interact with people is obviously from me outwards, whether that's students, or colleagues, or line managers, or people I line-manage.

Anne

Anne is ambitious to progress further in senior management but frank about what that will involve:

I think it's just a question of finding the right opportunity and deciding whether I'm willing to compromise who I am in order to get the jobs, if you see what I mean.

Meanwhile, Tom's career has progressed faster than expected:

I have been promoted above where I should be at this point in my career. I think I have been bumped up a couple of spots... I am now at a bit of a crossroads. I could go down the senior management route and that would be fine, or I could try and keep both sides (administration and research) going. I enjoy both, but research is valued more highly.

Tom, Senior Lecturer, White British, Male, 20-29 years

Despite success 'on paper' in terms of career progression, Tom's map and his accompanying narrative strongly suggest a sense of alienation. He chooses the triangle, draws four lines in it to represent levels of seniority throughout the organisation, then places a dot outside and below the triangle.

It is very hierarchically organised. In an ideal university the students would be at the top. My role is somewhere in the middle. But me, who I am, what I do, my hopes, my dreams, my aspirations, that is not interesting or important to anybody. I feel relatively powerless to affect change in any meaningful way in my institution. Tom 
In contrast to Tom and despite her expertise, Reeta feels her career has stagnated. As the sector goes through rapid change, 'space-time ... always under construction ... never finished, never closed' (Massey 2005, p. 9), she experiences conflicts between research and teaching:

I did my degree and then I ended up in industry for about twelve years first. HE is definitely one place where I haven't really progressed compared to all the jobs I've had in industry. My students are always satisfied. I get everything done on time. I like to think that my work speaks for itself - but now there's this massive push on writing and research, and I can't fit the time in physically.

Reeta, Senior Lecturer, Female, British Asian, 40+ years

Reeta feels stuck. Yvonne struggles to establish herself in the prestige economy. Anne's working life has been shaped by the endemic precarity of academic roles. Tom reluctantly faces choosing between academic research and management. As interviewer, I was alert to ways in which blocks, interruptions, stagnation and serendipity shape and complicate the 'career' path. Very few of the stories-so-far gathered for this project align with linear, uninterrupted, upward career progress. If as a researcher, I acknowledge and respect the complexity in these research findings, then this leads me as diversity worker to argue for more nuanced and intersectional understanding of the factors impacting every individuals' experiences of the workplace, those identifying as male and gender fluid or non-binary as well as female.

\section{Gender and Identity}

Jo performs a balancing act between her professional and personal lives:

It seems to me a suit and tie can get you into all sorts of places - but only if you're a man. As an adult, my performativity, certainly out of work, is very much more male than female. My performativity in work has leaned a bit more towards obviously female, now that I'm more senior because you just spend too much time having to reassure people and it's just so tedious having to accommodate their confusion. I think it has a huge impact, I think it's certainly limited my career now, I think I've gone as far as I can because I don't conform sufficiently.

Jo, Senior Professional Services Manager, White British, Female, 50+ years

Resisting sexism in the academy means not only challenging a 'one-size-fits-all' model of career but also being careful that, while weighted towards female disadvantage in the HE workplace, implementing the Athena SWAN framework does not 'reinforce essentialist and heteronormative assumptions that all women live in nuclear families... nor 'ignore differing cultural and social capital relating to social class, age, sexualities, disabilities and ethnicities (Morley 2013, p. 122). As Yvonne says: I think what a shame Athena SWAN has been reduced to - how can we all become more confident? I think the different ways of being a woman are maybe still not visible.

Reeta experiences not only the conflicting demands of research and teaching, but of balancing personal, professional and cultural identities, at work and at home:

People talk about dual identity in terms of being a professional in the industry and then being academic. Well, I've got that, but then I've got the whole cultural thing too. There was an expectation from me, as a daughter-in-law, living in my husband's family's house, that balancing act was really quite hard. I'm British, born here and embraced being here, but then there's a lot about my own culture that I do like. So, there's that balance as well.

In the mapping exercise, she chooses the rectangle shaded blue with a solid outline and places herself just inside:

I've been boxed into an identity, because I think my department see me as a mother before a professional and it's only because I made a bit of noise about it that I've been given more opportunities now. I think if one of my male colleagues had had a kid tomorrow, they're not going to say, 'Oh, he's got kids. He can't do this or that.'

Reeta 


\section{Institutional Speech Acts?}

The Athena SWAN Charter champions parental leave and flexible working arrangements and its Awards emphasise institutional obligations to address and mitigate the impact of gendered primary care responsibilities on working lives and careers. However, Lena's story-so-far reveals it is quite possible to implement legal requirements without tackling underlying structural bias.

I went on maternity leave. When I came back I was suddenly reporting to a new colleague. When I was finally promoted to the same level as him I was fascinated to discover that I wasn't being paid the same, because he had negotiated a higher starting salary. We have a flexible working policy. I work from home one day a week but I often feel as though I'm having to justify it, to say, 'Well, no, it's fine, because look, there's a piece of paper that says the University signed up to it'. There's this notion that flexible working is somehow something that women ask for and therefore it is something which is basically irritating to an organisation because it's some kind of extension of maternity leave and maternity leave is an irritation as well. Although flexible working is this term that is used about accommodating work and life for everybody in the $21^{\text {st }}$ century, it's actually a kind of workaround to shoehorn an old-fashioned career pattern into something which you have to try and make work around the commitments that you can't change.

Lena, Professional Services Manager, Female, White British, 30+ years

Lena distinguishes between the university's commitments to equality on paper, and attitudes and behaviours which sustain institutional and individual sexist practices. Maternity leave and flexible working arrangements are presented as an employee benefit, but women's absence from working spaces can reinforce male ownership of those spaces and a hidden curriculum of influential informal networks. If the complex lived experiences of parental leave and flexible working are silenced in corporate conversations then, as Ahmed describes it: 'institutional speech acts... do not go beyond pluralist understandings of diversity and are nonperformative in the sense that they fail to deliver what they have promised' (2006, p. 764).

Consideration of wider organisational culture is a key element of the Athena SWAN process. Applicants are required to reflect on workload, role models, outreach activities and accessibility of corporate social events. They must also quantitatively record gender balance in senior academic and managerial roles, in key committees and decision-making processes. These data are valuable. Numbers can shock, motivate and encourage - but resisting sexism is not just a numbers game. Tom draws attention to ways in which a gendered geography of power is enacted via microaggressions in meeting behaviours.

There is often an expectation in meetings, there is a particular kind of conversational style the male academics are meant to engage in. In the most diplomatic terms, very forthright "I am always right, everyone else is wrong, I will stick to my opinion, I will think that everyone else is not seeing the full picture'. I've never been comfortable with that kind of confrontational style of interaction. I don't engage in that at all... If there is a gender dimension here at all that would be it for me. I try to have a more co-operative style of conversation. Whether that has put me at a disadvantage I don't know.

Tom

Anne refers to her own experiences of resisting sexism within the workplace and of the strain this exacts on her.

I think people would think twice about saying something inappropriate in meetings I'm in. In another audience they may think that was amusing, to throw a comment in. But they never would do it in front of me, because they know I would jump on them. The trouble with that is, I do feel like I end up being the kind of feminist police a bit, which is a bit wearing.

Anne

\section{CONCLUDING REMARKS}

In Gender(s) at Work I use spatial storytelling to map and report stories beyond dominant and exclusionary narratives; to reveal the way gender operates as a geography of power in the academy, to uncover spaces between. Even this small selection of stories-so-far reflects the multidimensionality of gendered and intersectional lived experiences within the contested space of the university. Spatial storytelling foregrounds 
relationships between spaces and power. Reading the 'spatial' in these stories-so-far emphasises not only the material and metaphorical power structures of the academy, but also a psychosocial sense of gender as a geography of power in terms of peripherality, constraints and powerlessness.

Throughout the process of writing this chapter I have been reflecting on the alignments and tensions within my dual role: as an academic researcher and as an Athena SWAN Project Manager in the same university. Without the catalyst of Athena SWAN the already glacially slow progress towards gender equality in HE might become frozen over. However, I recognise Athena SWAN as entangled in and identified with an established geography of power within the academy which promotes and privileges a linear, uninterrupted career trajectory. This inevitably limits the Charter's capacity to structurally redress inequality's silences, discrimination and exclusions.

My research role enables me to bring criticality to my role as organisational diversity worker and to the normative career model. Resisting sexism in the academy means making visible the mechanisms that have bumped Tom up 'a couple of spots' and directing corporate effort into understanding 'how women can be supported to achieve their aspirations and flourish in HE without being damaged and impeded by patriarchal practices and norms' (Morley 2013, p. 116). It means continually questioning whether equality and diversity policies are being used as 'masks to create the appearance of being transformed' (Ahmed 2017); whether 'complaints can be stopped by the appearance of being heard' (Ahmed 2018). Resisting sexism in the academy is about removing the mask and raising the volume. I regard my research practice as a form of activism towards that end.

\section{REFERENCES}

Acker, J. (2006). Inequality regimes gender, class, and race in organizations. Gender \& Society, 20(4), 441-464.

Advance HE. (2018a). About Advance HE's Athena SWAN Charter. https://www.ecu.ac.uk/equalitycharters/athena-swan/about-athena-swan/. Last accessed September 2018.

Advance HE. (2018b). Athena SWAN members. https://www.ecu.ac.uk/equality-charters/athena-swan/athenaswan-members. Last accessed September 2018.

Advance HE. (2018c). Athena SWAN review. https://www.advance-he.ac.uk/news-and-views/advance-heannounces-athena-swan-review. Last accessed September 2018.

Ahmed, S. (2018, June 28). Refusal, resignation and complaint. Feministkilljoys. https://feministkilljoys.com/2018/06/28/refusal-resignation-and-complaint/. Last accessed September 2018.

Ahmed, S. (2017). Living a feminist life. Durham, NC: Duke University Press.

Ahmed, S. (2006). The nonperformativity of antiracism. Meridians: Feminism, Race, Transnationalism, 7(1), 104-126.

Allen, M., \& Castleman, T. (2001). The 'Pipeline Fallacy' and gender inequality in Higher Education employment. Policy, Organisation and Society, 15(1), 23-44.

Bagilhole, B. (2007). Challenging women in the male academy: Think about draining the swamp. In P. Cotterill, S. Jackson and G. Letherby (Eds.), Challenges and negotiations for women in Higher Education (pp. 2132). Dordrecht, Netherlands: Springer.

Bagilhole, B. (2002) Challenging Equal Opportunities: Changing and adapting male hegemony in academia, British Journal of Sociology of Education, 23(1), 19-3.

Bathmaker, A.-M. (2010). Introduction. In A.-M. Bathmaker and P. Hartnett (Eds.), Exploring learning, identity and power through life history and narrative research (pp. 1-10). London, UK: Routledge.

Bhopal, K. (2016). The experiences of Black and Minority Ethnic academics: A comparative study of the unequal academy. London and New York: Routledge.

Bilimoria, D., O'Neil, D. A., Hopkins, M. M., \& Murphy, V. (2010). Gender in the management education classroom: A collaborative learning journey. Journal of Management Education, 34(6), 848-873.

Blackmore, J. (2014). Wasting talent: Gender and the problematics of disenchantment and disengagement with leadership. Higher Education Research and Development 33(1), 86-99.

Blackmore, J., Sanchez-Moreno \& Sawars, N. (2015). Globalised re/gendering of the academy and leadership. Gender and Education, 27(3), iii-vii.

Brown, J., \& Jones, A. (2015, December). Joining the dots: making connections between institutional research, HE research, policy and practice. Conference paper at annual Society for Research into Higher Education (SRHE) conference, Newport, Wales.

Burkinshaw, P., \& White, K. (2017). Fixing the women or fixing universities: Women in HE Leadership. Administrative Sciences, 7(30), 1-14. 
Carruthers Thomas, K. (in press). Rethinking student belonging in Higher Education: From Bourdieu to Borderlands. London, UK: Routledge.

Carruthers Thomas, K. (2018). Athena SWAN: Principles and practice (Unpublished research). Birmingham City University, Birmingham, UK.

Carruthers Thomas, K. (2017). Towards a methodology: Organisational cartographies. International Journal of Professional Management: Special Issue Arts and Management, 12(3), 55-64.

Coate, K., Kandiko-Howson, C., \& de St Croix, T. (2015). The prestige economy and mid-career academic women: Strategies, choices and motivation. The Leadership Foundation for Higher Education report. https://www.srhe.ac.uk/conference2015/abstracts/0002.pdf. Last accessed September 2018.

Connelly, M., \& Clandinin, D. J. (1990). Stories of experience and narrative inquiry. Educational Researcher, 19(5), 2-14.

Creswell, J. W. (2007). Qualitative inquiry and research design: choosing among five approaches. Thousand Oaks, CA: Sage.

Equality Challenge Unit (ECU). (2018). http://www.ecu.ac.uk. Last accessed September 2018.

Gabriel, D., \& Tate, S. A. (Eds.). (2017). Inside the Ivory Tower. Narratives of women of colour surviving and thriving in British academia. Stoke-on-Trent, UK: Trentham Books.

Higher Education Funding Council for England (HEFCE). (2015). Equality and diversity in the 2014 Research Excellence Framework. Bristol, UK: HEFCE.

Jarboe, N. (2016). Women leaders in Higher Education. WomenCount. https://womencountblog.files.wordpress.com/2016/03/women-count-2016-leaders-in-he-020316.pdf. Last accessed September 2018.

Jones, L. (2018, February 5). What is the gender pay gap? BBC News. https://www.bbc.co.uk/news/business42918951. Last accessed September 2018.

Kesby, M. (2000). Participatory diagramming: deploying qualitative methods through an action research epistemology. Area, 32(4), 423-435.

Lynch, K. (2010). Carelessness: A hidden doxa of higher education. Arts and Humanities in Higher Education, 9(1), 54-67.

Lynch, K., \& Feely, M. (2009). Gender and education (and employment): Gendered imperatives and their implications for women and men. Lessons from research for policy makers. European Commission, Brussels. http://www.nesse.fr/nesse/activities/reports/gender-report-pdf. Last accessed September 2018.

McDowell, L. (1999). Gender, identity and place: understanding feminist geographies. Cambridge, UK: Polity Press.

Massey, D. (2005). For space. London, UK: Sage.

Massey, D. (1998). High-tech in Cambridge. In R. Ainley (Ed.), New frontiers of space, bodies and gender (pp. 157-175). London, UK: Routledge.

Morley, L. (2016). Troubling interactions: Gender, neo-liberalism and research in the global academy. Journal of Education Policy, 31(1), 28-45.

Morley, L. (2014). Lost leaders: women in the global academy. Higher Education Research and Development, 33(1), 114-128.

Morley, L. (2013). The rules of the game: Women and the leaderist turn in higher education. Gender and Education, 25(1), 116-131.

Morley, L., \& David, M. (2009). Celebrations and challenges: Gender in higher education. Higher Education Policy, 22(1), 1-2.

Noble, D. (1992). A world without women: the Christian clerical culture of Western science. New York, NY: Alfred A. Knopf.

O' Connor, P. (2014). Management and gender in Higher Education. Manchester, UK: Manchester University Press.

Rose, G. (2014). On the relation between 'visual research methods' and contemporary visual culture. The Sociological Review, 62, 24-46.

Solnit, R. (2001). Wanderlust: A history of walking. London, UK: Verso.

Solnit, R. (2006). A field guide to getting lost. Edinburgh, Scotland: Canongate.

Solnit, R. (2013). Unfathomable city: A New Orleans Atlas. Berkeley, CA: University of California Press.

Solnit, R. (2010). Infinite city: A San Francisco Atlas. Berkeley, CA: University of California Press.

Tate, S. A., \& Bagguley, P. (2017). Building the anti-racist university: next steps. Race, Ethnicity and Education, 20(3), 289-299. 
Thomas, K. (2016). Dimensions of belonging: Rethinking retention for mature part-time undergraduates in English Higher Education (Unpublished doctoral dissertation). University of London, London, UK.

White, K., \& O'Connor, P. (Eds.). (2017). Gendered success in Higher Education: Global perspectives. London, UK: Palgrave Macmillan.

Yarrow, E. (2017). National research evaluation and its effects on female academics' careers in the UK (Unpublished doctoral dissertation). Queen Mary University of London, London, UK. 